\title{
Simulation of long-term stem diameter variation of Ficus benjamina based on simulated transpiration
}

\author{
H.A.L. Van de Put, F.S. Lauriks, D.J.W. De Pauw and K. Steppe \\ Laboratory of Plant Ecology, Department of Applied Ecology and Environmental Biology, Faculty of Bioscience \\ Engineering, Ghent University, Coupure Links 653, 9000 Ghent, Belgium \\ hans.vandeput@UGent.be
}

\begin{abstract}
Greenhouse microclimate (light, temperature, relative humidity and $\mathrm{CO}_{2}$ ) and irrigation are important factors for plant growth, development and quality in ornamental horticulture. To optimize plant growth, actual stem diameter growth can be measured and compared with a desired growth pattern. Using the deviation between measured and simulated stem diameter growth, growers can decide whether and in which way the microclimate or irrigation needs to be adjusted. Together with this decision, costs associated with climate control and irrigation must also be taken into account. This will help growers to find a proper balance between cultivation costs and plant growth. In this study, Ficus benjamina was grown from cutting to mature plant in a controlled greenhouse environment. Growing conditions, microclimate as well as plant spacing, closely resembled the ones used in commercial greenhouses. Microclimate, soil water content, leaf temperature, sap flow, stem diameter variation and leaf thickness were continuously measured on three plants. In addition, discrete measurements of leaf area, projected crown surface area, stem water potential, photosynthesis, transpiration and stomatal conductance were performed. These measurements were used to further extend a mechanistic plant model, which allows simulation of long-term stem diameter variation.
\end{abstract}

Key words: ornamental horticulture, mechanistic modelling, plant monitoring, sap flow, stem diameter, leaf thickness

\section{INTRODUCTION}

Ornamental horticulture in greenhouses is characterised by high energy costs. In temperate regions, energy typically constitutes the second major production cost of greenhouse crops, following labour expenses (Runkle and Both, 2011). In Belgium, the share of agriculture in the total energy consumption was 2.3\% in 2010 (Eurostat). Most of this energy can be assigned to intensive greenhouse farming because supplementary heating and/or lighting are needed (Eurostat; Langton and Hamer, 2003). Together with the expected rise in energy prices (Capros et al., 2013), the need to remain competitive by improving energy efficiency increases.

Various energy efficient measures already caused a 50\% reduction in fuel use per unit product in the Netherlands from 1990 to 2014 (van der Velden and Smit, 2014). These measures include the use of combined heat and power systems, but also measures that directly or indirectly affect the greenhouse microclimate, like improving greenhouse insulation, installing thermal screens or changing the microclimatic set points of the greenhouse (Dueck et al., 2004; Langton and Hamer, 2003). Some changes in microclimatic set points have been tested for Ficus plants by Dueck et al. (2004). An increase in relative humidity by $5 \%$ resulted in a decrease in natural gas use of $2.5 \%$ and an increase in production of $2 \%$. Decreasing the overall greenhouse temperature by $2{ }^{\circ} \mathrm{C}$ led to a decrease of $14 \%$ in natural gas use and a decrease in production of $8 \%$. According to a survey of the Greenhouse Growers magazine in 2001, most of the responding growers (22\%) actually lowered growing temperature in response to the rising fuel costs (Runkle, 2006). This illustrates that energy efficiency increasing measures can affect greenhouse microclimate, and as a consequence also plant growth and quality. 
This brings up the need for a monitoring system in which plant growth under new, energy efficient measures can be compared to growth under standard growing condition. In this research, the first steps towards such a system are taken by extending an existing plant model (Steppe et al., 2006; De Swaef and Steppe, 2010) to simulate long-term stem diameter variation based on simulated transpiration instead of measured sap flow. Being able to simulate transpiration based on microclimate is crucial to couple this process-based plant model to a greenhouse model to calculate energy costs. Modelling transpiration also allows assessing the impact of specific microclimatic settings on the plant response, and vice versa.

\section{MATERIALS AND METHOD}

\section{Experimental setup}

Ficus plants (Ficus benjamina) were grown from cutting on a substrate mixture (Peltracom, Ghent, Belgium) on four cultivation tables in a $90 \mathrm{~m}^{2}$ greenhouse compartment of the Ornamental Plant Research Centre (PCS) in Destelbergen, Belgium. Plant density was approximately 15 pots per $\mathrm{m}^{2}$, where every pot contained 3 cuttings. The experiment started on 23 March 2016. Greenhouse microclimate was set by controlling the window openings, a thermal screen, an air

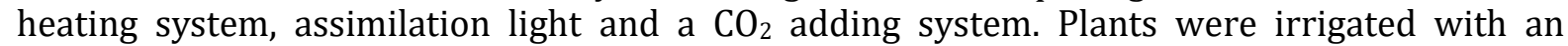
automatic flood irrigation system, controlled by time and radiation sum. Set points for microclimate and irrigation control were similar to the ones used in commercial greenhouses.

\section{Microclimatic measurements}

The microclimate of the greenhouse was continuously monitored. Photosynthetic active radiation (PAR) and $\mathrm{CO}_{2}$ concentration were measured with a LI-190 Quantum Sensor (LI-COR, Lincoln, Nebraska, USA) and a carbon dioxide probe (Vaisala CARBOCAP GMP343, Vantaa, Finland), respectively. Temperature and relative humidity were measured with a temperature and relative humidity probe (Campbell Scientific CS215, Logan, UT, USA), which was installed in a ventilated radiation shield.

\section{Continuous plant measurements}

Stem diameter variations and sap flow were continuously monitored on three plants with, respectively, a linear variable displacement transducer (LVDT, Solartron, Bognor Regis, UK) and a custom-built mini-HRM (Heat Ratio Method) sensor. Also, a leaf thickness sensor (LeafSen, Hefer, Israel) was used to measure leaf thickness and stem diameter of thinner stem segments on three plants.

\section{Discrete plant measurements}

Leaf area and projected crown surface area were measured at intervals of one to three weeks. In addition, an average daily pattern of stomatal conductance was measured with a porometer (AP4, Delta-T Devices, Cambridge, UK) using five plants on 21 April (one leaf per plant per hour and a half) and ten plants on 31 May (one leaf per plant per two hours). At these days and with the same measurement frequency, a daily pattern of stem water potential was also measured on two and three plants on 21 April and 31 May, respectively, with a thermocouple psychrometer, consisting of a chamber (C-52, Wescor, Logan, UT, US), a switch box (PS-10, Wescor, Logan, UT, US) and a dewpoint microvoltmeter (HR-33T, Wescor, Logan, UT, US). On 21 April, a portable photosynthesis system (LI-6400XT, LI-COR, Lincoln, Nebraska, USA) was used

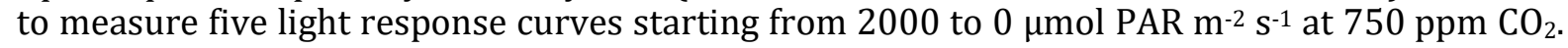
Light levels were maintained until equilibrium.

\section{Model calibration and simulation}


The plant model of De Swaef and Steppe (2010), based on the original plant model of Steppe et al. (2006), was used to simulate stem diameter variation. Measured stem diameter variations and xylem water potential are used for model calibration. First, xylem water potential is calibrated by adjusting two parameters: stem hydraulic resistance and xylem water potential at night. Then stem diameter variation is calibrated. Four parameters have to be adjusted: the hydraulic capacitance, elasticity of the living tissue, bulk cell wall extensibility and a time constant for an increase in extensibility of the following form: 1-e-time/time constant. Hydraulic capacitance and elasticity are assumed to be independent of plant age during simulation and were determined during a calibration over the first 4 days of the long-term simulation, while the bulk cell wall extensibility and the time constant for the change in extensibility were determined using the 35 days dataset. An identifiability analysis (De Pauw et al., 2008) of the model showed that the selected parameter-set could be calibrated.

Instead of measured sap flow, which typically serves as input to the model, simulated plant transpiration is used as input. This transpiration is simulated with the Penman-Monteith equation (Monteith and Unsworth, 2013), extended with a term for light extinction in the canopy (Bailey et al., 1993). Stomatal conductance is simulated with an adjusted version (Leuning, 1995) of the semi-empirical model for stomatal behavior of Ball et al. (1987) and used as input to the Penman-Monteith equation. Photosynthesis in the stomatal conductance model is based on a rectangular hyperbola, which was fitted to the average of the measured light response curves. For the rectangular hyperbola, two parameters have to be calibrated: the initial slope of the light response curve and the photosynthetic rate at light saturation. In the stomatal conductance model, a parameter for stomatal conductance at night and a scaling factor of stomatal conductance to photosynthesis, vapor pressure deficit and $\mathrm{CO}_{2}$ concentration need to be calibrated. This stomatal conductance is used in the Penman-Monteith equation, along with the projected crown surface area and leaf area index. The models for stomatal conductance and transpiration were calibrated together.

Model calibration, simulation and identifiability analysis were performed with the plant modeling software PhytoSim (Phyto-IT BVBA, Mariakerke, Belgium). For calibration, the Simplex method (Nelder and Mead, 1965) was used to minimize the weighted sum of squared errors. Simulations were done using a fourth-order Runge-Kutta numerical integrator with a fixed step size of $0.1 \mathrm{~h}$.

\section{RESULTS AND DISCUSSION}

The fitted rectangular hyperbola corresponded well to the mean light response curve (Fig. 1). The light response curves were measured at $750 \mathrm{ppm} \mathrm{CO}_{2}$, while the experiment was carried out at approximately $500 \mathrm{ppm} \mathrm{CO}_{2}$ due to a sensor failure in the greenhouse facility. The light response curve at $500 \mathrm{ppm}$ is expected to have a lower photosynthetic rate at light saturation, but the general shape will be similar. Therefore, the light response curve at $750 \mathrm{ppm}$ was used in the stomatal conductance model. The scaling factor of the stomatal conductance would be higher if a light response curve at $500 \mathrm{ppm}$ would have been used, but the simulated stomatal conductance is expected to be similar.

For a good agreement between the measured and simulated stomatal conductance on 21 April and 31 May (Fig. 2 and Fig. 3, respectively), a decreasing scaling factor was assumed in the stomatal conductance model. Simulated stomatal conductance, in turn, is used in the PenmanMonteith equation to simulate transpiration (Fig. 4). The projected crown surface area and leaf area index were measured during the simulation period and changed from approximately $98 \mathrm{~cm}^{2}$ to $203 \mathrm{~cm}^{2}$ and 1.5 to 2.1, respectively. Measured sap flow and simulated transpiration corresponded very well at the start of the simulation, but near the end, simulated transpiration was mostly higher than measured sap flow. A possible explanation is that stomatal conductance was only measured on fully developed, mature leaves at the top of the plant, while the younger and older leaves are expected to have a lower stomatal conductance (Constable and Rawson, 
1980). This was also confirmed in our own study by a number of stomatal conductance measurements on leaves with different age (mature, older and younger) of one of the Ficus plants. As the portion of older leaves increases with maturation, the decrease in overall stomatal conductance is expected to be higher than the one measured from 21 April to 31 May.

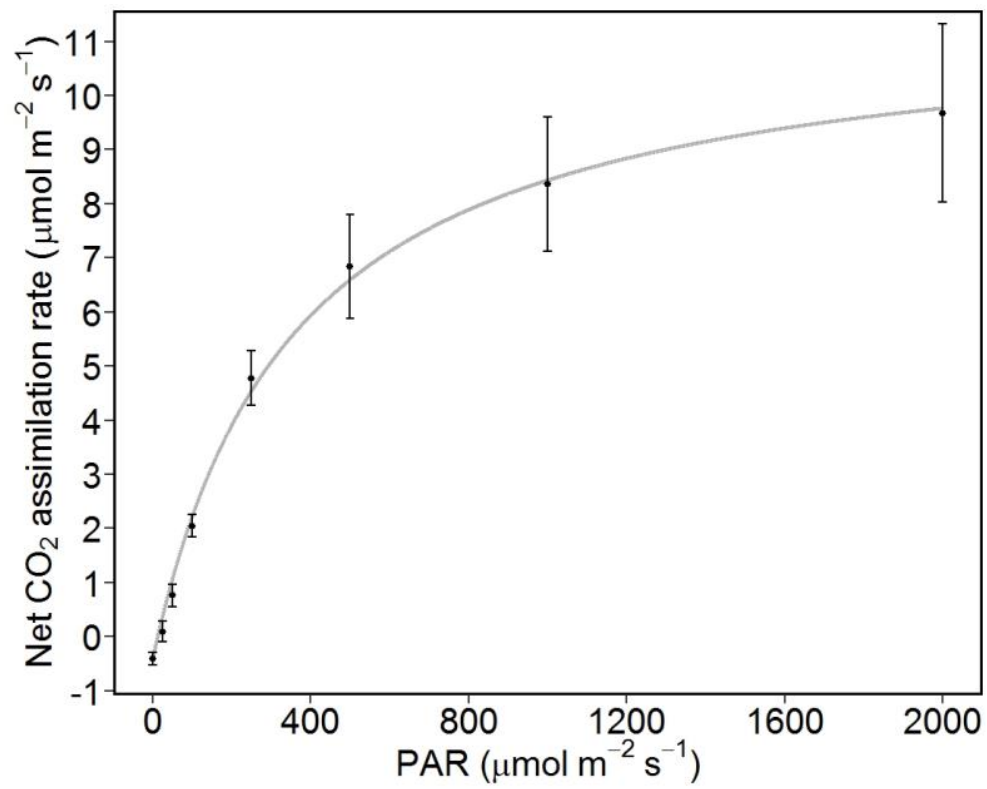

Fig. 1. Mean value $\left( \pm \mathrm{SD}, \mathrm{n}=5\right.$ ) of measured net $\mathrm{CO}_{2}$ assimilation rate at different levels of photosynthetic active radiation (black dots and bars) on 21 April. A light response curve was fitted to the measured data using a rectangular hyperbola (grey line).

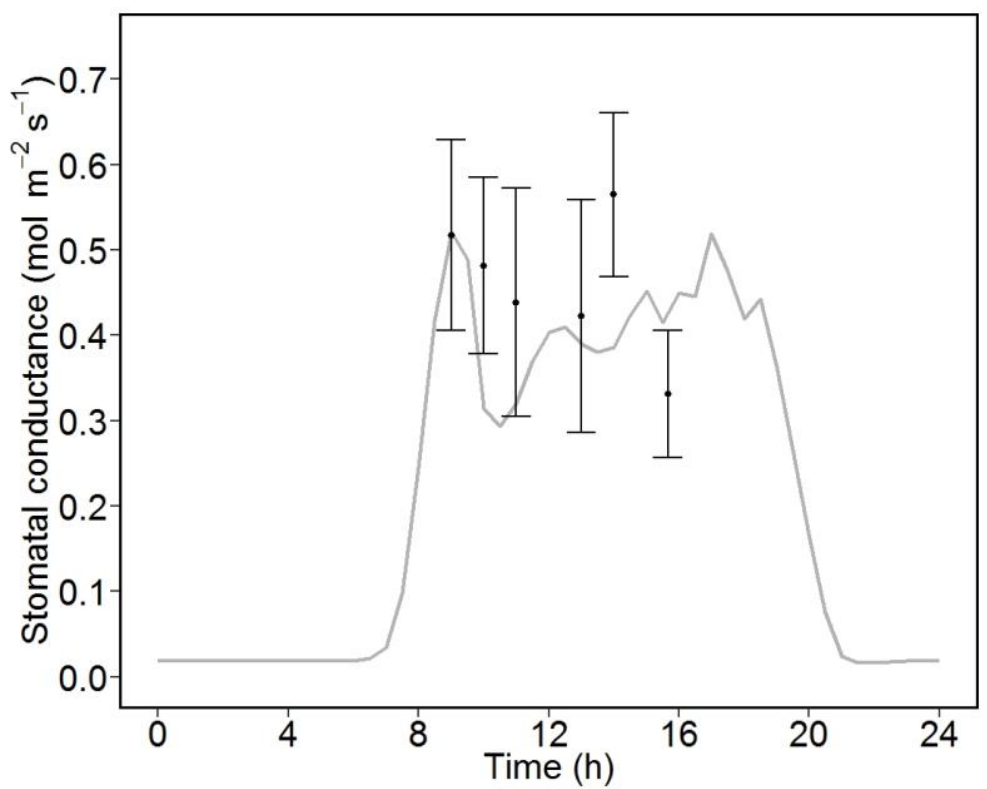

Fig. 2. Mean values $( \pm S D, n=5)$ of measured stomatal conductance (black dots and bars) and simulated stomatal conductance (grey line) on 21 April. 


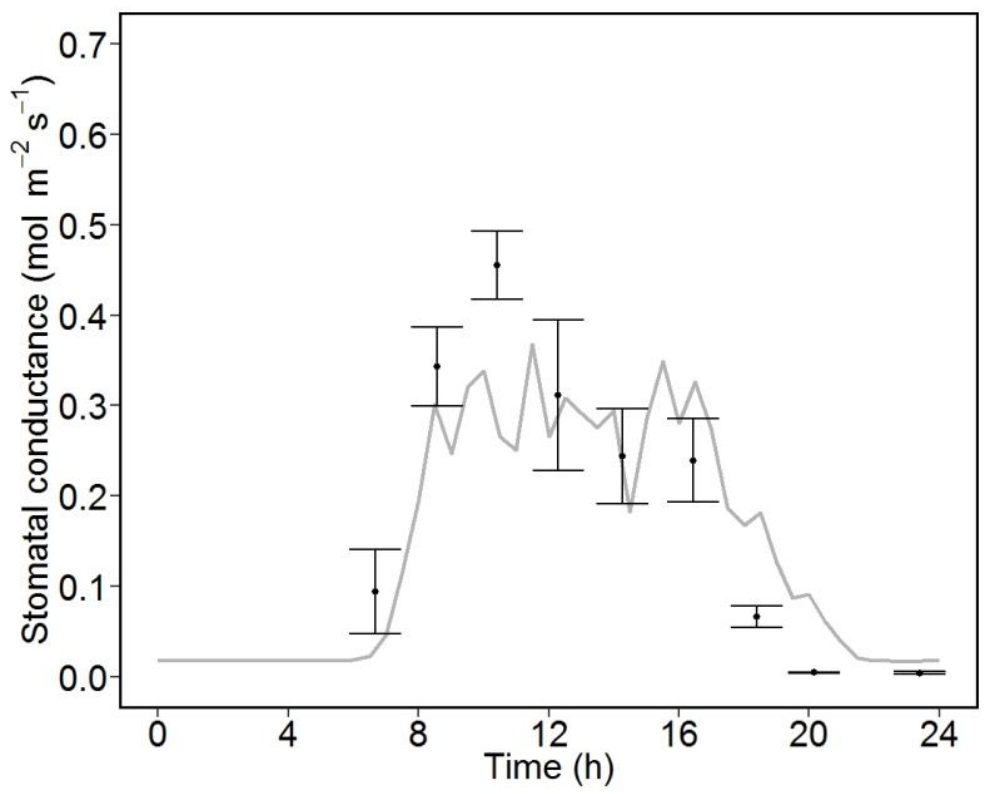

Fig. 3. Mean values $( \pm S D, n=10)$ of measured stomatal conductance (black dots and bars) and simulated stomatal conductance (grey line) on 31 May.

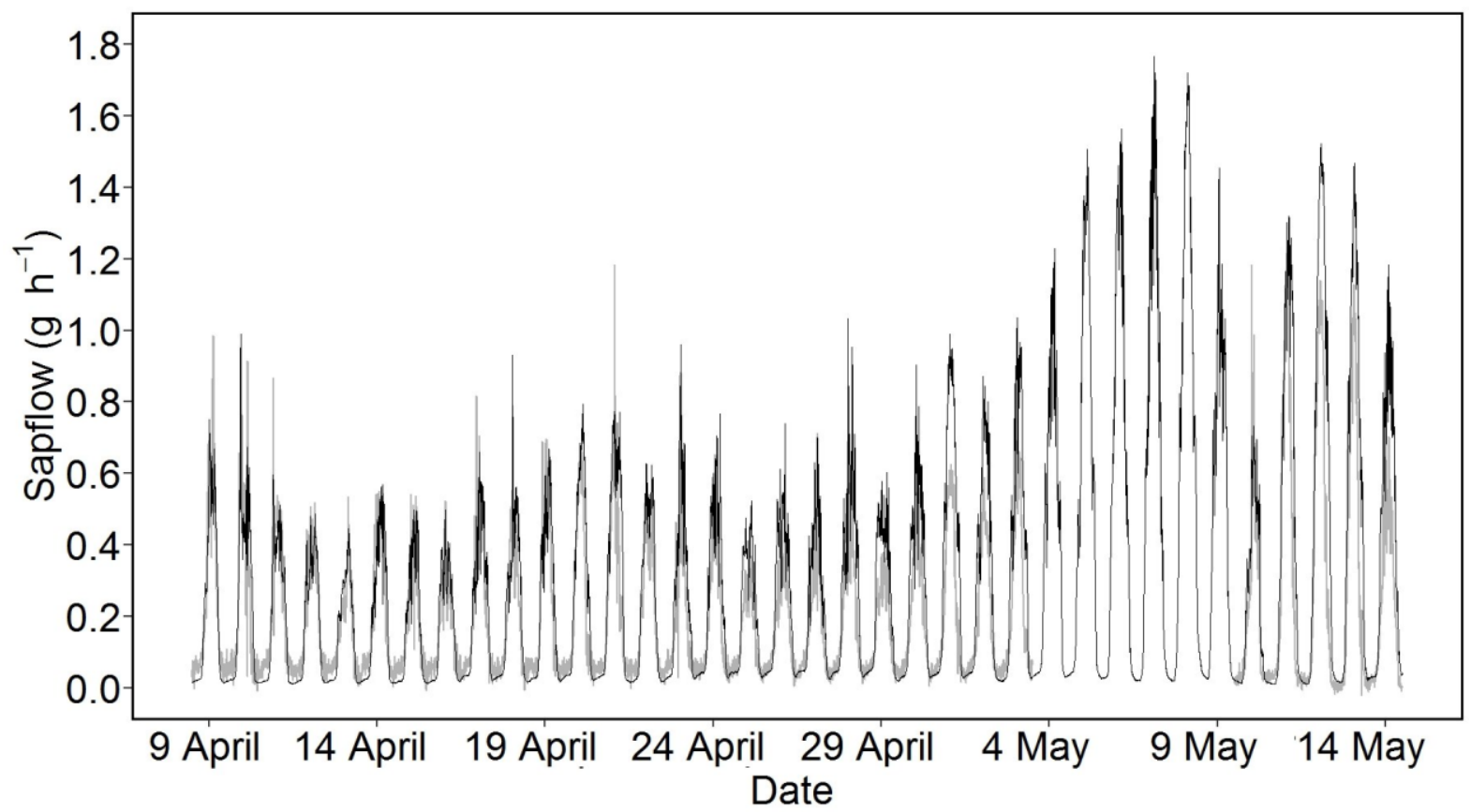

Fig. 4. Measured sap flow (grey line) and simulated transpiration (black line) as a function of the number of days after simulation started. No measured sap flow is available from 4 to 9 May.

Stem diameter variation and stem growth were simulated over a period of 35 days, starting from 9 April using simulated transpiration as input. A good correspondence was found between simulated and measured xylem water potential on 21 April, which was expected as these measurements were used for calibration (Fig. 5). Measured and simulated xylem water potentials 
were also compared on 31 May, with a good correspondence for night and noon values. Simulated daily stem diameter dynamics are also in good agreement with the measured ones (Fig. 6), except on three days (6-8 May). These days are characterized by a higher than expected stem shrinkage, possibly due to stress caused by unusually high temperatures $\left(>35^{\circ} \mathrm{C}\right)$ or drought stress caused by non-optimal water supply at higher temperatures. Deviation between measured and simulated daily stem diameter dynamics shows that the model can be used for drought stress detection. All model parameters remained unchanged during the entire simulation period. Cell wall extensibility was implemented to change during the simulation by using a bulk cell wall extensibility and a time constant. This was needed because measured stem diameter growth was not linear across the measured period.

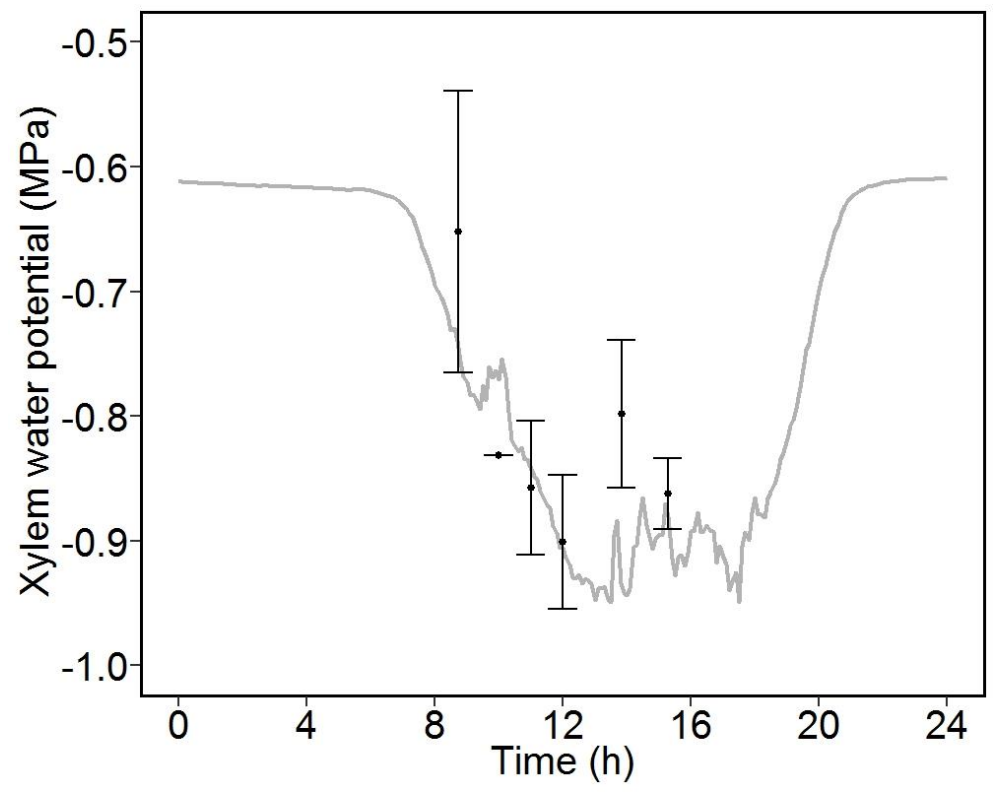

Fig. 5. Mean values $( \pm S D, n=2$ ) of measured (black dots and bars) and simulated (grey line) xylem water potential on 21 April. 


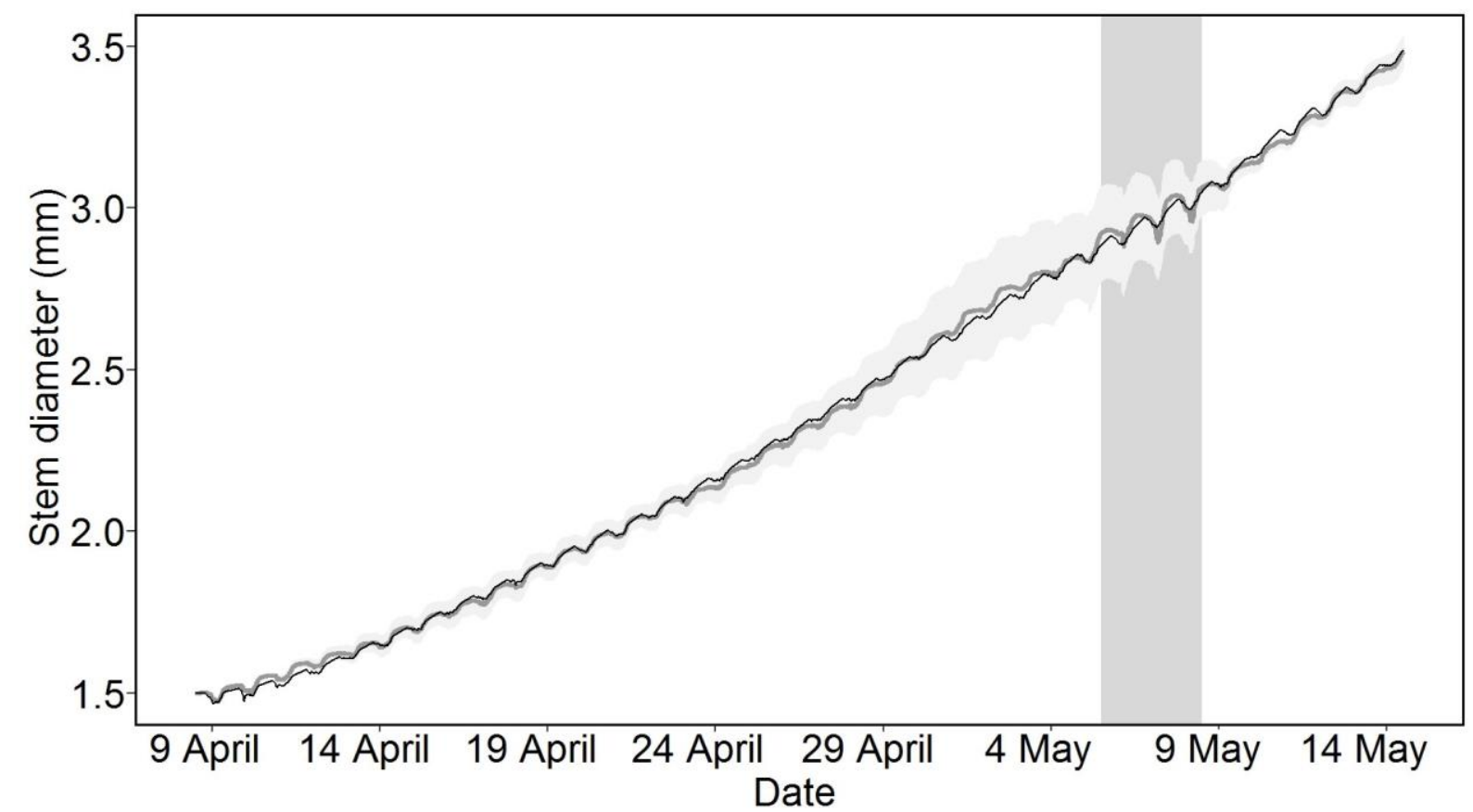

Fig. 6. Average measured (grey line) and simulated (black line) stem diameter as a function of the number of days after simulation started. The light grey band gives the standard deviation $(n=3)$ on the average measured stem diameter variation. The period of a less good agreement between the simulated and measured stem diameter (6-8 May) is highlighted in dark grey.

The model based on simulated transpiration performed well. This is an important step towards the development of an integrated plant-greenhouse model in which the interaction between plant response and greenhouse microclimate settings is crucial. Moreover, simulated transpiration can be used when sap flow measurements are impossible. A further improvement to the model could be the use of the Farquhar model instead of a rectangular hyperbola to simulate photosynthesis. The physiological background of this model allows for simulations in a wider range of environmental conditions, such as changing temperature or $\mathrm{CO}_{2}$ concentration. Also, implementation of changes in leaf stomatal conductance during plant development could improve the model output. In order to predict stem diameter growth and variation solely based on environmental variables, it should be investigated whether also cell wall extensibility, projected crown surface area and leaf area index could be described based on microclimate or another easy to measure driving variable.

\section{CONCLUSIONS}

Long-term stem diameter variations of Ficus benjamina were successfully simulated using simulated transpiration as an input to the model. Using simulated transpiration instead of measured sap flow opens up opportunities to predict the interactions between plant and greenhouse microclimate, which is necessary when the plant model is coupled to a greenhouse model. This can assist growers in their decision taking with respect to greenhouse microclimate settings, and the related effects on plant function and growth.

\section{ACKNOWLEDGEMENTS}

The authors thank the Agency for Innovation by Science and Technology in Flanders (IWT) for granting the funding of the Sense-IT LA-trajectory to Kathy Steppe, which supports the PhD 
funding of Hans Van de Put and Fran Lauriks. The authors are also grateful to Philip Deman, Geert Favyts and Erik Moerman for their technical support during the experiment and to Bert Schamp and the staff at PCS for the counsel and attendance of all plant material.

\section{Literature cited}

Bailey, B.J., Montero, J.I., Biel, C., Wilkinson, D.J., Anton, A., and Jolliet, O. (1993). Transpiration of Ficus benjamina: comparison of measurements with predictions of the Penman-Monteith model and a simplified version. Agricultural and Forest Meteorology 65 (3), 229-243 http://dx.doi.org/10.1016/0168-1923(93)90006-4.

Ball, J.T., Woodrow, I.E. and Berry, J.A. (1987). A model predicting stomatal conductance and its contribution to the control of photosynthesis under different environmental conditions. Progress in Photosynthesis Research (Leiden, The Netherlands: Martinus Nijhoff Publishers), p. 221-224 http://dx.doi.org/10.1007/978-94-017-0519-6_48.

Capros, P., De Vita, A., Tasios, N., Papadopoulos, D., Siskos, P., Apostolaki, E., Zampara, M., Paroussos, L., Fragiadakis, K., Kouvaritakis, N., et al. (2013). EU Energy, Transport and GHG Emissions Trends to 2050: Reference Scenario 2013. (Luxembourg, Luxembourg: Publications Office of the European Union), pp. 17.

Constable, G.A., and Rawson, H.M. (1980). Effect of leaf position, expansion and age on photosynthesis, transpiration and water use efficiency of cotton. Functional Plant Biology. 7 (1), 89-100 http://dx.doi.org/10.1071/PP9800089.

De Pauw, D.J.W., Steppe, K. and De Baets, B. (2008). Identifiability analysis and improvement of a tree water flow and storage model. Mathematical Biosciences 211(2), 314-332 http://dx.doi.org/10.1016/j.mbs.2007.08.007.

De Swaef, T., and Steppe, K. (2010) Linking stem diameter variations to sap flow, turgor and water potential in tomato. Functional Plant Biology 37 (5), 429-438 http://dx.doi.org/10.1071/FP09233.

Dueck, T., Elings, A., Kempkes, F., Knies, P., van de Braak, N, Garcia, N., Heij, G., Janse, J., Kaarsemaker, R., Korsten, P., et al. (2004). Energie in kengetallen: zoek naar een nieuwe balans. (Wageningen, The Netherlands: Plant Research International B.V.), p. 7-30.

Eurostat. (2015). ec.europa.eu/Eurostat.

Langton, F.A., and Hamer, P.J.C. (2003). Energy efficient production of high quality ornamental species. Final Report to Defra, project HH1330.

Leuning, R. (1995). A critical appraisal of a combined stomatal-photosynthesis model for C3 plants. Plant, Cell \& Environment 18 (4), 339-355 http://dx.doi.org/10.1111/j.1365-3040.1995.tb00370.x.

Monteith, J.L., and Unsworth, M.H. (2013). Principles of Environmental Physics, $4^{\text {th }}$ edn (Kidlington, Oxford, UK: Academic Press), p. 230-232.

Mooney, H.A., Field, C., Vásquez Yanes, C., and Chu, C. (1983). Environmental controls on stomatal conductance in a shrub of the humid tropics. Proc. Natl. Acad. Sci. 80, 1295-1297.

Nelder, J.A., and Mead, R. (1965), A simplex method for function minimization. The computer journal 7 (4), 308-313 http://dx.doi.org/10.1093/comjnl/7.4.308.

Runkle, E. (2006). Temperature Effects on Floriculture Crops and Energy Consumption. OFA Bulletin 894.

Runkle, E., and Both., A.J. (2011). Greenhouse Energy Conservation Strategies. Michigan State University Extension Bulletin E-3160.

Steppe, K., De Pauw, D.J., Lemeur, R., and Vanrolleghem, P.A. (2006) A mathematical model linking tree sap flow dynamics to daily stem diameter fluctuations and radial stem growth. Tree Physiology 26 (3), 257-273 http://dx.doi.org/10.1093/treephys/26.3.257.

van der Velden, N., and Smit, P. (2014). Energiemonitor van de Nederlandse glastuinbouw 2014. (Wageningen, The Netherlands: LEI), pp.18.

Xie, X., Wang, Y., Williamson, L., Holroyd, G.H., Tagliavia, C., Murchie, E., Theobald, J., Knight, M.R., Davies, W.J., Leyster, H.M.O., et al. (2006). The identification of genes involved in the stomatal response to reduced atmospheric relative humidity. Current Biology, 16 (9), 882-887 http://dx.doi.org/10.1016/j.cub.2006.03.028. 